\title{
A evolução dos jogos de Física, a avaliação formativa e a prática reflexiva do professor
}

\author{
(Physics games evolution, formative assessment and reflexive teacher practice)
}

Marli Cardoso Ferreiral e Lizete Maria Orquiza de Carvalho ${ }^{2}$

\author{
${ }^{1}$ Universidade Estadual Paulista “Júlio de Mesquita Filho”, Faculdade de Ciência e Tecnologia, \\ Departamento de Física, Química e Biologia, Presidente Prudente, SP, Brasil. \\ ${ }^{2}$ Universidade Estadual Paulista "Júlio de Mesquita Filho", Faculdade de Engenharia, \\ Departamento de Física e Química, Ilha Solteira, SP, Brasil.
}

\begin{abstract}
Este artigo analisa um processo reflexivo vivido ao longo de uma trajetória de desenvolvimento de jogos, sobre questões de Física, que foram criados por iniciativa de uma professora (MCF), em diferentes realidades do ensino médio. Duas fases foram identificadas: a primeira representou uma busca para tornar o ensino de física prazeroso; a segunda, sob influência da perspectiva teórica de Paul Black, materializou-se em resposta a uma indagação, feita pela professora, sobre quais elementos da avaliação formativa poderiam ser trabalhados no jogo. A análise também revelou que as influências interpessoais e teóricas vivenciadas pela professora, na segunda fase, foram determinantes para que, ao final da trajetória, ela pudesse reconhecer-se como uma "professora reflexiva".
\end{abstract}

Palavras-chave: jogos, Ensino Médio, avaliação formativa, professora reflexiva.

\begin{abstract}
This article analyzes a reflexive process lived along a trajectory of development of Physics games, created by a teacher (MCF), in high school distinct realities. Two phases were identified: the first was represented by her search to make physics teaching enjoyable; the second, under Paul Black theoretical perspective, was brought to reality in response to a question about which elements of formative assessment could be taken into account during games development. The analyses also revealed that interpersonal and theoretical influences lived by the teacher were determining for her to recognize herself as a "reflexive teacher", at the end of the trajectory.

Keywords: games, high school, formative assessment, reflexive teacher.
\end{abstract}

\section{Introdução}

Literatura recente tem se ocupado em caracterizar um modelo sobre a prática do professor que é chamado de "prática reflexiva". Para Schön [1], uma das características da prática reflexiva refere-se ao gerenciamento do relacionamento interpessoal. Esse autor acredita que, para o profissional, em sua prática, enfrentar domínios em princípio indeterminados, é importante ter um comportamento no grupo que implica alimentar atitudes de receptividade, abertura e aceitação mútua. É importante, ainda, que o profissional saiba sujeitar seus dilemas pessoais à investigação, no grupo, arriscando-se a expor o que realmente estiver pensando, e colocar em teste os sentimentos negativos que possa experimentar em relação a outros membros do grupo [(12, p.191)]. O artigo de Zeichner e Liston, 2001, p.6, apud, Geraldi, Messias e Guerra, 2001, cap. 9 [2], descreve qualidades do "professor reflexivo". Segundo esses autores, o professor reflexivo "examina, esboça e tenta resolver os dilemas da prática; está alerta a respeito das questões e assume os valores que carrega para o ensino; está atento para o contexto institucional e cultural; toma

Enviar correspondência para Marli Cardoso Ferreira: ammecf@stetnet. com.br. Lizete Maria Orquiza de Carvalho: lizete@fqm.feis.unesp.br. parte do desenvolvimento cultural e se envolve na sua mudança; assume responsabilidade por seu desenvolvimento profissional e procura trabalhar em grupo".

Nesse sentido, este artigo analisa um processo de reflexão vivido por uma professora (M.C.F.) ao longo de uma trajetória de prática e desenvolvimento de jogos instrucionais. Para melhor compreensão do processo, apresenta-se, inicialmente, uma descrição das atividades dos jogos e caracterizam-se as situações em que essas atividades foram desenvolvidas. Visando ainda à compreensão do processo de reflexão, apresenta-se, em seguida, uma interpretação sobre a evolução ocorrida nos jogos. Por último, registra-se a análise do processo de reflexão propriamente dito.

\section{Os jogos e seus contextos}

As atividades dos jogos ocorreram durante quatro anos (de 1998 a 2001), envolvendo alunos do ensino médio, em sala de aula, e estagiários de licenciatura, atuando nessas salas, além de vários professores da rede pública de ensino que também aplicaram os jogos.

É importante ressaltar que as condições em que os projetos ocorreram foram favoráveis à análise dos dados segundo metodologia qualitativa. Em primeiro lugar, todos 
os jogos estavam inseridos em contexto escolar, um ambiente não artificial de pesquisa. Segundo Ludke e André, "cada vez mais se entende o fenômeno educacional como situado dentro de um contexto social, por sua vez inserido em uma realidade histórica, que sofre toda uma série de determinações" ([3] p.5). Em segundo lugar, a qualidade da participação dos envolvidos nas atividades implicou desempenho de papéis ativos de todos os participantes - da professora-pesquisadora; dos elaboradores, em grupo de estudo; dos aplicadores, na sala de aula, e dos jogadores, em atividades de classe e extraclasse.

Durante quatro anos, a professora envolveu-se em seis projetos subseqüentes que, embora tivessem motivações diferentes, sempre acabaram por envolver jogos de Física. Nos dois primeiros, a motivação era desenvolver atividades criativas, na sala de aula de Física, em colaboração com professores da rede pública do Estado de São Paulo. No terceiro e no quarto, a motivação era envolver alunos do segundo grau em atividades de sala de aula. E, nos dois últimos, criar situações de sala de aula que permitissem à professora-pesquisadora refletir sobre como melhorar os jogos de Física. Durante os projetos, 33 jogos foram realizados. Os jogos dos dois primeiros projetos foram denominados de 'jogos de tabuleiro', por se distinguirem dos outros pelo uso do tabuleiro e de mini-carrinhos coloridos. A idéia de trabalhar com jogos surgiu no início do primeiro projeto, realizado com seis professores da rede pública. Uma dessas professoras mostrou aos demais um jogo, chamado de corrida maluca, que consistia em uma atividade lúdica, sem regras definidas, que podia ser realizado em tabuleiro de qualquer jogo em desuso, com minicarrinhos coloridos, dados, fichas interrogativas, contendo questões e informações da atualidade sobre Física. No segundo projeto - realizado com trinta professores da rede pública do Estado de São Paulo, no âmbito de um curso de capacitação $^{1}$ - a professora, motivada pelos resultados dos jogos com questões de Física, realizou as primeiras mudanças para aprimorá-los. Para atender à necessidade de reaplicação dos jogos e durabilidade do material, os esforços voltaram-se para a sofisticação do material do jogo. Assim, no segundo projeto, cada professor recebeu uma caixa de madeira personalizada e colorida, contendo material de jogo muito bem elaborado e organizado.

Os jogos do terceiro e quarto projetos foram denominados de 'jogos rápidos', pois ocorriam em um tempo de aplicação muito curto. Esses jogos foram desenvolvidos por alunos do ensino médio ou por futuros professores, sem a participação de M.C.F. No terceiro projeto, os jogos foram elaborados por alunos da terceira série do ensino médio da escola pública que tinham participado, enquanto jogadores, dos dois primeiros projetos. Além de dispensar o tabuleiro, esses alunos mudaram a dinâmica: o jogo, passou a ser em equipe, introduziu-se também o uso do cronômetro para marcar o tempo de resposta e, conseqüentemente, assegurar a marcação do ritmo do jogo. No quarto projeto, os jogos foram elaborados por sete futuros professores, que faziam estágio supervisionado nas classes de Ensino Médio porque a professora-pesquisadora era responsável ${ }^{2}$. Os futuros professores utilizaram os mesmos materiais do jogo anterior, introduzindo, porém, a roleta de bingo como elemento determinante da sorte.

Os jogos do quinto e sexto projetos foram denominados de jogos "passo a passo", pois, apesar de conservarem a maioria das características dos jogos do quarto projeto, apresentavam desdobramento em etapas e ganharam acréscimo no tempo de espera, tanto para que os jogadores se preparassem para a próxima etapa como para que as ações se completassem em cada uma delas. Uma outra novidade consistiu na confecção de material para ser estudado pelos alunos antes do início das atividades do jogo (cerca de 14 dias). O quinto projeto realizado por exigência de uma disciplina de pós-graduação ${ }^{3}$. Uma das tarefas propostas pela professora da disciplina consistia em criar situações pedagógicas favoráveis à aprendizagem de algum conceito físico. Para realizar essa tarefa, a professora-pesquisadora juntou-se a outra aluna da disciplina para realizar um jogo sobre o tema "energia". O jogo foi aplicado na primeira série do ensino médio em que a professora-pesquisadora ministrava aulas. No sexto projeto, quatro futuros professores ${ }^{4}$ participaram das atividades de elaboração dos jogos sobre o conceito de pressão, junto com a professorapesquisadora. Com o objetivo de "levar o aluno pensar", o grupo elaborou questões abertas e reflexivas, com diferentes graus de complexidade, o que acabou ocasionando aumento imprevisto do número de encontros, tanto entre elaboradores como entre esses e os jogadores. $\mathrm{O}$ uso ambíguo do cronômetro na marcação do tempo de resposta combinava-se com os alunos que o tempo de resposta seria de 2 minutos, mas, na verdade, esperava-se que os grupos finalizassem as discussões para o aplicador avisar que o tempo se esgotara - visava tanto organizar a atenção dos alunos na atividade de grupo como permitir tempo necessário de discussão. Como uma última novidade, na véspera das rodadas do jogo, os grupos receberam um envelope lacrado, contendo questões, denominado de passaporte, cujas respostas davam direito de ingresso à próxima etapa.

\section{Interpretando a evolução dos jogos}

A partir do ingresso no curso de pós-graduação, ocorrido no ano de 2000, a professora entrou em contato com artigos de Black e Wiliam ([4] e [5]) sobre avaliação formativa. É importante ressaltar que esse referencial não trata diretamente de jogos de Física, mas oferece subsídios à

1 Pró-ciências/FAPESP.

2 Esses futuros professores cursavam a disciplina de Prática de Ensino de Física no curso de licenciatura em Matemática da FCT/Unesp - P. Prudente.

3 Didática das Ciências, no curso de pós-graduação em Educação para a Ciências - FC/Unesp - Bauru, que a professorapesquisadora freqüientava como aluna.

4 Dois desses futuros professores já haviam participado do desenvolvimento e implementação do jogo no quarto projeto; os outros dois não conheciam a professora-pesquisadora até o inicio desse estágio. 
reflexão sobre a interação professor/aluno em sala de aula e sobre a elaboração de questões, no ensino de ciências. Esses autores utilizam a expressão "avaliação formativa" para se referirem a todas as atividades empreendidas pelos professores e seus alunos que fornecem informação usada como feedback para modificar as atividades de ensino e de aprendizagem. Segundo eles, o trabalho do professor deve visar "livrar os alunos da armadilha do baixo rendimento", quando é o caso, e desenvolver "hábitos necessários para todos os alunos se tornarem aprendizes para toda a vida" ([4] e [5]).

Não decorreu muito tempo até que a professora-pesquisadora reconhecesse no novo referencial uma fonte de inspiração para prosseguir com seus esforços de aprimoramento dos jogos. A análise das modificações introduzidas nos jogos, principalmente no quinto e sexto projetos, permite perceber algumas marcas da influência desse referencial.

A primeira diz respeito ao tempo de espera concedido aos alunos para responderem às questões. As variações introduzidas nos jogos "passo a passo" resultaram tanto no aumento do tempo permitido para a resposta como na flexibilidade da cobrança desse tempo pelos aplicadores. Segundo Black e Harrison [6], o procedimento de esperar o tempo necessário para que haja reflexão e discussão própria dos alunos é fundamental para que o "conteúdo real e as formas de procedimentos da resposta se tornem importantes para os alunos" [6].

A segunda relaciona-se às responsabilidades individuais e coletivas de fornecerem respostas às questões. As regras de quase todos os jogos previam questões de andamento e de fechamento dos jogos. Com as mudanças de regras, ao longo dos projetos, as questões de andamento do jogo que, no início, eram uma responsabilidade individual, no final passaram a ser responsabilidade do grupo. Já as questões de fechamento, no início, eram responsabilidade do grupo e, depois, passaram a ser responsabilidade do indivíduo. Interpreta-se que esse movimento inverso significou um caminhar para o aumento de possibilidade de feedback entre os alunos e entre professor e aluno, pois as respostas dadas às questões de fechamento eram sempre corrigidas pelo professor ([4] e [5]).

A terceira refere-se à necessidade de preparo dos jogadores para o jogo e o decorrente aumento da necessidade de os elaboradores prepararem o assunto a ser trabalhado no jogo. Conseqüentemente, houve aumento do número de informações trocadas e aumento das possibilidades de construção de relações entre informações durante as discussões em grupo, tanto durante os jogos como durante os estudos extraclasse.

A quarta liga-se à melhoria da qualidade das questões, que ocorreu segundo cinco eixos: quanto à forma de apresentação do enunciado, quanto à complexidade dos raciocínios envolvidos, quanto ao conteúdo, quanto ao tratamento do conteúdo e quanto aos processos psicológicos a que os jogos com questões fazem apelo [7]. Segundo Black e Harrison, é importante que os professores, para melhorarem a avaliação formativa, mudem "suas formas de fazer perguntas em sala de aula" [6].
A quinta está relacionada ao fato de a função do jogo ter evoluído de função de fechamento - nos quatro primeiros projetos, o jogo era realizados na última de uma série de aulas previstas para dado tópico - para função de desenvolvimento de um conteúdo - nos dois últimos projetos, os jogos eram realizados em vários momentos durante o ensino de um dado tópico. Isso implicou considerar que os elaboradores do jogo não poderiam mais deixar de refletir sobre as adaptações necessárias que os professores têm de fazer para promover a aprendizagem dos alunos. Segundo Black e Wiliam, as oportunidades de os alunos expressarem suas compreensões deveriam ser projetadas para qualquer parte do ensino, pois assim se "iniciará a interação pela qual a avaliação formativa ajuda a aprendizagem" ([4] e [5]).

A sexta refere-se ao aumento imprevisto do número de encontros do grupo de elaboradores, no sexto projeto. Tal fato decorreu da disposição do grupo de implementar adaptações às atividades, respondendo a necessidades que percebiam, durante a interação com os alunos. Isso está de acordo com a afirmação de Black e Wiliam, para quem "o usuário fundamental do aperfeiçoamento da aprendizagem é o aluno" ([4] e [5]). Segundo esses autores, somente quando são realizadas "adaptações do ensino às necessidades dos alunos" a avaliação torna-se formativa [5].

\section{A Reflexão da professora-pesquisadora}

Quanto ao processo de reflexão sobre a ação docente, vivido pela professora-pesquisadora, definem-se duas fases, cujo marco divisório foi seu ingresso no curso de mestrado, no ano de 2000. A análise dessas fases tem como referência as categorias de Martinez [8]. Essa autora faz um paralelo entre a auto-avaliação do aluno ([4] e[5]) e a reflexão do professor sobre sua ação docente, com a finalidade de construir categorias sobre a reflexão que o professor faz quando está estudando um referencial teórico e tentando aplicá-lo à sua prática. Segundo Black e Wiliam [4], a comparação entre o estado presente e o padrão de referência, no contexto da auto-avaliação do aluno, pode ser feita em termos de igualdade (são o mesmo ou são diferente?), distância (quão longe estão um do outro?) e diagnose (o que é necessário fazer para chegar até lá?). Para Martinez, o professor somente se coloca a terceira questão após solucionar possíveis conflitos vivenciados no contato com o referencial teórico. Neste momento, ele elege determinado padrão de referência, dentro do quadro teórico, como valor particular. Segundo essa autora, um gap focaliza uma lacuna, detectada pelo professor, entre o nível de referência, associado ao quadro teórico, e o nível de referência reconhecido por ele, na sua prática. Portanto, entende-se que a gap implica a perspectiva da auto-avaliação do aluno ou da reflexão do professor sobre sua ação, uma vez que introduz o reconhecimento de um desnível de valor.

\subsection{Primeira fase: aprender deve ser uma atividade prazerosa}

Nesta fase, os esforços da professora-pesquisadora estavam voltados para a tentativa de despertar a motivação interna [9], tanto dos jogadores como dos elaboradores dos jogos. Ao propor as atividades, sempre abria a possibili- 
dade de que eles poderiam sugerir outras, se não gostassem daquelas. Nessa época, os referenciais teóricos nos quais se apoiava eram, predominantemente, livros didáticos, livros paradidáticos e revistas científicas. A partir de 1999, no entanto, passou a estudar os parâmetros curriculares nacionais (PCN's) para o ensino médio [10]. Esses estudos redirecionaram seus esforços para a elaboração de instrumentos que estimulassem, no aluno, o interesse por conhecer o mundo físico e suas leis, a partir de procedimentos de experimentação essenciais para o desenvolvimento da autonomia intelectual necessária ao exercício da cidadania. Uma característica da professora-pesquisadora, que já se manifestava nesta época, era certa inquietude constante para a contínua criação que se manifestava.

Aplicando as categorias de Martinez, o tipo de gap que pode ser reconhecido como característico da primeira fase do trabalho da professora-pesquisadora é o gap de transbordamento $^{5}$, o que significa que ela se sentia repleta de saberes [11] - que podem ser descritos como "saber ouvir aos alunos e professores, para fazê-los perceber que aprender é prazeroso" e "saber buscar novas idéias para construir novas atividades em uma enorme variedade de fontes" - e queria compartilhá-los com outras pessoas.

\subsection{A segunda fase: em busca da qualidade de aprendizagem}

As primeiras indagações surgiram no primeiro semestre de 2000, por ocasião das aulas e discussões do grupo de pesquisa, ambos ligados ao curso de pós-graduação que passara a freqüentar. Reflexão posterior levou-a a perceber e admitir o que antes era inaceitável, ou seja, que os alunos, nos jogos, apesar de interessados e envolvidos, não apresentavam mudanças significativas em termos de aproveitamento e aprendizagem. Porém, inquieta diante dessa possibilidade, dispôs-se ao enfrentamento da questão.

Segundo o referencial de Martinez, o gap enfrentado, nesse momento, pode ser caracterizado como gap contemplativo. Segundo a autora, esse gap caracteriza-se pela reação do professor quando reconhece que a lacuna é muito grande para ser redimensionada ou fechada de imediato. Diante da lacuna, suspende a ação imediata, passando a contemplar possíveis caminhos de fechamento do gap. Apesar de não desistir do empenho de aprimoramento dos jogos, sabia que havia um longo caminho a ser percorrido para melhoria da qualidade dos mesmos. Nessa busca, uma leitura marcante foi o artigo de Wells [12] sobre a avaliação do trabalho coletivo, quando passou a distinguir alguns fundamentos do trabalho cooperativo: pluralidade, espírito de solidariedade e socialização do saber. Lançou-se, então, em uma atividade conjunta com os futuros professores, buscando um encaminhamento para suas indagações através da prática. Dispôs-se a criar atividades que lhe permitissem refletir, em ação, sobre quais seriam as mudanças que poderiam ser implementadas em busca da melhoria da qualidade dos jogos. Utilizando a linguagem de Martinez [8], seria este um gap ativo, pois a professora-pesquisadora desencadeou uma ação efetiva para fechar a lacuna, isto é, sugeriu ações para alcançar a meta. Isso significa que ela reelaborou o status da lacuna, anteriormente percebida como muito grande, concebendo-a como suportável e, até mesmo, desafiadora.

\section{Conclusões}

A busca por caminhos possíveis de desenvolvimento e aplicação dos jogos, pela professora-pesquisadora, ocorreu sempre dentro do contexto da reflexão na ação [13]. Na primeira fase, a reflexão era pouco influenciada pela discussão sobre teorias pedagógicas; já na segunda fase, a influência dessa discussão foi decisiva para os rumos tomados pelas mudanças. Enquanto, na primeira fase, as ações eram construídas, seguindo duas orientações - de um lado, o conteúdo a ser trabalhado e, de outro, a seqüência e organização das atividades - , na segunda, as ações eram construídas a partir de questões que relacionavam a prática com as teorias estudadas, sofrendo nítidas influências do diálogo com grupos ligados ao programa de mestrado. Dessa forma, se, nos projetos iniciais, suas preocupações eram mais de professora, à medida que os projetos foram se sucedendo, o papel de professora-pesquisadora foi emergindo e, aos poucos, se impondo.

Apesar de não haver estreita correspondência entre os 6 (seis) projetos dos jogos e as 2 (duas) fases do processo de reflexão da professora-pesquisadora, a instauração da segunda fase foi decisiva para desencadear as mudanças introduzidas nos últimos projetos dos jogos, quando ocorreu o aumento significativo das possibilidades de reflexão do aluno sobre o conteúdo. O contato com os trabalhos de Black e Wiliam [5] sobre aprendizagem e avaliação formativa foi decisivo para o surgimento da questão principal quais elementos da avaliação formativa podem ser trabalhados com o jogo?- que acabou levando às inovações implementadas nos últimos projetos.

Os ganhos advindos das experiências de ter enfrentado a situação conflituosa caracterizada pela percepção de que, "apesar de interessados e envolvidos, os alunos não apresentavam mudanças significativas em termos de aproveitamento e aprendizagem" e de ter trabalhado para "transformar o gap contemplativo em um gap ativo" estão ligados ao desenvolvimento de competências que o professor deve desenvolver para enfrentar as zonas indeterminadas de sua prática profissional [1].

Da trajetória da professora-pesquisadora, concluí-se que somente o seu envolvimento pessoal e genuíno com um quadro teórico possibilitou sua entrada num processo de desenvolvimento. Assim, acredita-se que esse envolvimento é uma condição indispensável para que o professor se torne reflexivo, conforme a definição de Zeichner e Liston [2], citada no primeiro parágrafo deste artigo.

\section{Referências}

[1] D.A. Schön, Educando o profissional reflexivo: um novo design para o ensino e a aprendizagem (Porto Alegre, Artmed, 2000), $256 \mathrm{p}$. 
[2] C.M.G. Geraldi, M.G.M. Messias, e M.D.S. Guerra, Refletindo com Zeichner: um encontro orientado por preocupações políticas, teóricas e epistemológicas, organizado por D. Fiorentini, E. M. de A. Pereira e C.M.G. Geraldi, Cartografias do Trabalho Docente (Mercado das Letras, Campinas, 2001), p. 237-274.

[3] M. Ludke e M.E.D.A. André, Pesquisa em Educação: Abordagens Qualitativas (EPU, São Paulo, 1986), p. 99.

[4] P. Black and D. Willian, Assessment and classroom learning. Assessment in Education 5, 1 (1998a), p. 7.

[5] P. Black and D. Willian. Inside the Black Box: Raising Standerd Through Classroom Assessment. Assessment in education. Disponível em: http://www.pdkintl.org/kappan/ kbla9810.htm.ov.1998b. Acesso em: 6 abr. 2000 (1998b).

[6] P. Black and C. Harrison. Feedback in Question and Marking: The Science Teacher's Role in Formative Assessment. School science review 83, 55 (2001).

[7] L.M. Orquiza de Carvalho e M.C. Ferreira, A Evolução de Jogos com Questões de Física, in: VIII Conferencia Interamericana sobre Educacion em la Física, 8, 2003, Havana.
Atas... Havana: Sociedade Cubana de Física. Disponível em CD-Rom, p. 1-7 (2003).

[8] C.L.P. Martinez, Explorando o Potencial da Avaliação Formativa: Análise de uma Experiência Centrada na Escola. Dissertação de Mestrado em Educação para a Ciência, Faculdade de Ciências, Universidade Estadual Paulista "Júlio de Mesquita Filho", Bauru, 2001.

[9] E.L Deci and; R.M. Ryan, Promoting Self-determined Education. Scandinavian Journal of Education Research 38, 3 (1994).

[10] Brasil, Ministério da Educação, Parâmetros Curriculares Nacionais: Ensino Médio (MEC, Brasília, 1999), 360 p.

[11] M. Tardif, Saberes Profissionais dos Professores e Conhecimentos Universitários. Revista Brasileira de Educação 13, 5 (2000).

[12] G. Wells, Da Adivinhação à Previsão: Discurso Progressivo no Ensino e na Aprendizagem de Ciências, organizado por C. Coll e D. Edwards, Ensino, Aprendizagem e Discurso em Sala de Aula: Aproximações ao Discurso Educacional (Artmed, Porto Alegre, 1998), p. 107-142.

[13] K.M. Zeinchner, A Formação Reflexiva de Professores (Educa, Lisboa, 1993), 131 p. 